\title{
Charting a course to support military families navigating service systems for children with Autism Spectrum Disorder: A qualitative study
}

\author{
Heidi Crammª, Ronald Garth Smith ${ }^{\mathrm{b}}$, Dawa Samdup ${ }^{\mathrm{b}}$, Ashley Williams ${ }^{\mathrm{a}}$ and Lucia Ruhland
}

\begin{abstract}
Introduction: Most military families experience mandatory relocation, or posting, several times during their military career. For Canadian military families, who must access provincial or territorial health care systems, maintaining reasonable continuity of care is a persistent issue. Such challenges may be amplified when a child in a military family has special needs within the health and educational systems. The purpose of this qualitative study was to gain a better understanding of Canadian Armed Forces (CAF) families' experiences in navigating health care systems on behalf of a child with Autism Spectrum Disorder (ASD), in the context of mandatory relocation, and to determine their recommendations for improved system navigation. Methods: Parents of children with ASD, where at least one parent serves in the CAF and had faced military-related relocation, were recruited. Semi-structured interviews were recorded, transcribed verbatim, and analyzed thematically. Results: A total of 13 participants represented 12 families and 15 children with ASD. Participants discussed two primary ways to support military families: (1) Improve communication between military-connected families with children with ASD, and (2) Improve transition coordination. Discussion: The recommendations made by military families echo those made in clinical professional association reports and recent Canadian research. International policy initiatives to offset the impacts of military family relocation may serve as examples to adapt to the provincial and territorial jurisdictions for both health and education in Canada.
\end{abstract}

Key words: Autism Spectrum Disorder, children with autism, health care system, mandatory relocation, military family, phenomenology, qualitative study, school system, system navigation

\section{RÉSUMÉ}

Introduction : La plupart des familles des militaires sont tenues de se réinstaller - ou d'accepter de nouvelles affectations - plusieurs fois au long de la carrière du militaire. Pour les familles de militaires canadiens qui doivent accéder au réseau de la santé provincial ou territorial, une continuité raisonnable des soins représente un enjeu constant. Ce problème peut être amplifié lorsque l'un des enfants de la famille a des besoins particuliers au sein des réseaux de la santé et de léducation. La présente étude qualitative visait à mieux comprendre les expériences des familles des membres des Forces armées canadiennes qui doivent s'orienter dans le réseau de la santé pour leur enfant ayant un trouble du spectre de l'autisme (TSA) après une réinstallation obligatoire, ainsi qu'à connaître leurs recommandations pour mieux s'orienter dans le réseau. Méthodologie : Les chercheurs ont recruté les parents d'enfants ayant un TSA si au moins l'un des parents servait dans les Forces armées canadiennes et si la famille avait vécu une réinstallation militaire. Ils ont enregistré les entrevues semi-structurées, les ont transcrites textuellement et les ont analysées par thèmes. Résultats : Treize participants, qui représentaient 12 familles et 15 enfants ayant un TSA, ont discuté de deux grands moyens de soutenir les familles des militaires : 1 . améliorer les communications entre les familles des militaires dont un enfant a un TSA et 2. améliorer la coordination de la transition. Discussion : Les recommandations formulées par les familles des militaires reprennent celles qui figurent dans les rapports d'associations de professionnels cliniciens et dans de récentes recherches canadiennes. Des initiatives stratégiques internationales conçues pour atténuer les répercussions des réinstallations des familles des militaires pourraient inspirer l'adaptation des réseaux de santé et d'éducation des régions juridictions provinciales et territoriales du Canada.

Mots-clés : étude qualitative, famille des militaires, orientation dans le système, phénoménologie, réseau de la santé, réseau scolaire, trouble du spectre de l'autisme

a School of Rehabilitation Therapy, Queen's University, Kingston, Ontario

b Department of Pediatrics, Queen's University, Kingston, Ontario

Correspondence should be addressed to Heidi Cramm at heidi.cramm@queensu.ca 


\begin{abstract}
LAY SUMMARY
Military families are familiar with the challenges of accessing health care and educational supports for their children when they are posted. When a child in a military family has special needs, these issues are even greater. This study involved interviews with parents of children with Autism Spectrum Disorder (ASD). We asked 13 parents about their experiences and what they would recommend to improve the situation. After reviewing the interviews for common themes, we identified two key areas: (1) Improve communication with other military families who have children with ASD, and (2) Improve coordination of services for families who are transitioning between locations.
\end{abstract}

\section{INTRODUCTION}

Military families commonly experience mandatory relocations, or "postings", to different military locations during a serving member's career within the Canadian Armed Forces (CAF). While there is limited research on the effect of mandatory military relocation on children, ${ }^{1}$ postings have been reported to be highly disruptive to family life and one of the most unsettling features of the military lifestyle in the United States (US) ${ }^{2,3}$ and Canada. ${ }^{4}$ This can be especially true when a family has a child with special needs. ${ }^{4-8}$ Military Family Services (MFS) has recognized that CAF families "supporting a family member with special needs have unique and additional challenges, beyond those faced by civilian Canadian families, as a direct result of the CAF lifestyle."

ASD is a relatively common neurobehavioural condition of childhood, with Health Canada recently reporting the prevalence of ASD as 1 in 66 children between the ages of $5-17 .{ }^{10}$ Children who have ASD typically require more frequent and broad access to educational and health care services ${ }^{11,12}$ to address impairments in social communication, which present in combination with repetitive and restrictive behaviours and sensitivities, including sensitivity to changes in routine. ${ }^{13}$ Early diagnosis is critical, as treatment at an early age has been found to have the greatest impact on the prognosis of ASD, but the increased rates over the past 10 years have resulted in wait-lists of up to 2 years for diagnosis, typically by a developmental pediatrician. ${ }^{14}$ This congestion further delays access to other required services. ${ }^{15}$ These issues are compounded for military families, with postings disrupting the process of obtaining a diagnosis and/or treatment. ${ }^{6,16,17}$ Several studies document challenges American military families face when navigating services and supports for children with special needs after being posted to a new location, ${ }^{5-8}$ including increased risk for high stress levels and challenges accessing and maintaining ASD services. ${ }^{16,17}$

In Canada, $8.2 \%$ of military families are reported to have a child with special needs such as ASD. ${ }^{18}$ Most research conducted on the impact of relocation in Canada includes non-peer reviewed research (e.g., government reports) and indicates frequent relocations are the most challenging aspect of military life, and that finding health care in this context is extremely difficult. ${ }^{19-21}$ Additionally, frequent relocation disrupts academic participation and performance for military-connected children due to differing requirements across regions and provinces..$^{22,23}$

There has been some peer-reviewed research published on military relocation in the United States, ${ }^{1}$ but this literature is lacking in Canada. There are some crucial differences between the American and Canadian military family health care service delivery systems that may limit the generalizability of the American findings to Canada. In the United States, the Department of Defense's military health care system provides services to military personnel and their families, which helps maintain continuity of care for the entire family during relocation. ${ }^{11}$ By contrast, unless the posting is international or remote, Canadian Forces Health Services provides medical care only to military personnel, while families are required to access civilian provincial and territorial health care services. Moreover, the level of specific resource development to support parents in their children's educational transition differs. In the United States, the Military Interstate Children's Compact Commission has offices in 50 member states that help families address education transition issues when they are relocated. ${ }^{24}$ Military OneSource is a call center that provides information, referrals, and access specifically related to special needs. ${ }^{6}$ In Canada, recent funding has been devoted to further development of special-needs services within the Miltiary Family Resource Centres, but, ultimately, the services are variable across locations. ${ }^{25}$

With limited data on the specific issues Canadian military families face when navigating what is often a complex web of health and educational services and supports, this research explored the experience of Canadian 
military families navigating health and education systems on behalf of children with ASD and determined recommendations families would make to support others facing mandatory relocation. The results regarding participants' experience of health service navigation are reported elsewhere. ${ }^{26}$ The purpose of this article is to present and discuss participants' recommendations in light of their experience navigating health and educational services. A better understanding of the recommendations from the family perspective may ultimately translate into better practices and policies to reduce stressors on military families when they are relocated.

\section{METHODS}

\section{Design}

A qualitative phenomenological approach was used to investigate the lived experience of Canadian military familes who have children with ASD and are navigating the health and educational systems in Canada in the context of relocation. This included participants' perspectives on how to improve access to these systems, which is the subject of this article.

\section{Participants}

Eligible participants included parents in a Canadian military family (i.e., a family with at least one parent serving in the CAF) with at least one child with ASD and either experienced a posting or elected to leave the CAF Regular Forces to avoid it.

\section{Recruitment}

Posters were placed in ASD service agencies in the region of two military bases, along with Facebook and Twitter. Sixteen families inquired about the study, with three not responding further and one declining to participate. A sample size of 15-20 was sought, which is within the general guidelines for phenomenological studies, ${ }^{27}$ and participants were recruited until theoretical saturation was achieved ${ }^{27}$ and no new information was obtained from participants.

\section{Procedure}

The semi-structured interview guide was piloted $(n=1)$, refined, and implemented (HC, AW) for use in face-toface or phone interviews with participants. As suggested by Lester, ${ }^{28}$ the interview guide was loosely structured to enquire about several key areas. For this study, these key areas included pathways through the health care system during relocation, barriers faced when trying to navigate systems and supports, and what types of resources would have been, or could be, helpful in navigating health care for children with ASD in military families. The latter of these key areas is the focus of this article and questions related to participant recommendations can be found in Table 1. Field notes were made during/after interviews. This study was granted ethical clearance (\#6016307) by the Queen's University Health Sciences and Affiliated Teaching Hospitals Research Ethics Board.

\section{Data analysis}

All interviews were recorded and transcribed verbatim. Two of the authors used the constant comparison method to code the raw data ${ }^{29}$ with the assistance of qualitative data analysis software, MAXQDA (VERBI Software Consult Sozialforschung GmbH, Berlin, Germany). Analysts and the lead researcher compared and resolved coding disagreements to increase the validity of the findings ${ }^{30}$ repeatedly. Emergent themes were aggregated from the initial codes to capture the "essence" of participants' experiences and their recommendations based on these experiences.

\section{RESULTS}

Thirteen participants from 12 families were interviewed for an average of 63 minutes each, between January and August 2016, until the authors agreed no new information was being obtained (i.e., saturation was achieved). No repeat interviews were carried out. Nearly all participants were currently residing in Ontario and were married or cohabitating. The majority had only one family member in the CAF Regular Force, over half of whom

\section{Table 1. Sample interview questions}

1. In an ideal situation, what kinds of system supports or resources would be present to support you in navigating the new health care system and accessing the necessary services?

Prompts:

a. What aspects of different systems would you combine to create this ideal scenario?

b. If you had a magic wand, what kind of system change would you make to ease health system navigation and service access issues for military families who have children with ASD?

2. Is there anything else related to navigating health care systems for military families who have children with ASD that we haven't asked but is important for us to know?

ASD = Autism Spectrum Disorder. 
were non-commissioned members. See Table 2 for demographic information about the sample.

Participants described their experiences of navigating health services for their children with ASD in the

Table 2. Participant demographics

\begin{tabular}{|c|c|}
\hline Demographic characteristics & No.* \\
\hline Number of participants & 13 \\
\hline Number of families & 12 \\
\hline Number of dual CAF families & 4 \\
\hline Number of children with ASD & 15 \\
\hline Female & 5 \\
\hline Male & 10 \\
\hline \multicolumn{2}{|l|}{ Marital status } \\
\hline Married/cohabitating & 10 \\
\hline Separated & 1 \\
\hline Blended & 1 \\
\hline Age of diagnosis (years), range & $2-8.5$ \\
\hline $\begin{array}{l}\text { Current age of child with ASD } \\
\text { (years), range }\end{array}$ & $4-18$ \\
\hline $\begin{array}{l}\text { Number of postings after initial con- } \\
\text { tact with health care or education } \\
\text { system about ASD (years), range }\end{array}$ & $0-3$ \\
\hline \multicolumn{2}{|l|}{ Province of diagnosis } \\
\hline Ontario & 14 \\
\hline Manitoba & 1 \\
\hline \multicolumn{2}{|l|}{ Current provincial posting location } \\
\hline Ontario & 11 \\
\hline Alberta & 1 \\
\hline Previous provincial posting locations & $\begin{array}{l}\text { NS, QC, ON, } \\
M B, A B, B C\end{array}$ \\
\hline \multicolumn{2}{|l|}{ CAF member workforce designation } \\
\hline Regular & 12 \\
\hline Reserve & 0 \\
\hline \multicolumn{2}{|l|}{ Service element } \\
\hline Army & 9 \\
\hline Air Force & 2 \\
\hline Navy & 2 \\
\hline Not indicated & 3 \\
\hline \multicolumn{2}{|l|}{ Commission status } \\
\hline Non-commissioned officers & 10 \\
\hline Commissioned officers & 3 \\
\hline Not indicated & 3 \\
\hline
\end{tabular}

* Unless otherwise noted.

$\mathrm{CAF}=$ Canadian Armed Forces; ASD = Autism Spectrum Disorder; NS = Nova Scotia; $Q \mathrm{C}=$ Quebec; ON = Ontario; $\mathrm{MB}=$ Manitoba; $\mathrm{AB}=$ Alberta; $\mathrm{BC}=$ British Columbia. context of relocation. Three themes emerged: (1) High mobility inherent in the military lifestyle can create disruptions and discontinuities in service; (2) Navigating health systems for children with ASD takes its toll on military families; and (3) Opportunities to support military families navigating service systems for children with ASD. The third theme is the subject of this article; the first two themes are reported elsewhere. ${ }^{26}$ Opportunities to support military families thematically cluster around communication strategies and strategies to enhance continuity.

\section{Communication strategies}

\section{Informal support network}

When asked for recommendations to improve health care navigation, half of the participants suggested a network of informal supports - what one participant called a "network of shepherds" - be established at each base, comprised of families who have a child(ren) with ASD who could provide information and mentoring for new arrivals. Particularly valued was information from other parents of children with ASD who had been at the location for a few years. One parent said:

$[\mathrm{P}]$ eople who have been through the same thing you're going through are the best ones to talk to, because they can tell you, 'This is the doctor you need to see. This is the school. This is who you talk to at the school.' You need somebody who's been there.

Nearly all of these respondents suggested the network be coordinated outside the military command structure and "through the [Military Family Resource Centres (MFRC's)]." This type of network would be able to provide "not just the official information you get from the government ... which you can read in 15 minutes and isn't very helpful, but a network that is well-informed." The scope of information that a network could provide was essentially limitless. One participant stated: "That's where I've got almost all my information. People will phone me up and ask me questions, and so I try to pass on the same sort of information about everything."

\section{Point person at each base}

More than half of parents recommended there "be staff located at each base ... whose job is to help ... military families who are posted in, (who have special-needs kids), access the right services, just to navigate the provincial services. Because it's a huge thing for any special-needs parent to try and navigate the province, and 
the services available, but if you have to learn a different province every 3 years, you lose your mind."

At the same time, some participants expressed a need to take responsibility for making contacts during relocation and "not wait for anybody else." Overall, participants suggested the provision of streamlined assistance with this particularly complicated undertaking that is not of their choosing. One parent summarized the ideal: "A centralized location that deals specifically with children with special needs ... They know what has to be done when you move. One-stop shop for that." Another suggested that a combination of a point person and informal mentoring would work well.

\section{Enhanced and current information package prior to, and upon, transition}

Parents expressed the need for both general and specific information, depending on their familiarity with the new province's systems and where they are in the diagnosis and treatment pathway for their child with ASD. A couple of parents said general information included in the military welcome package would be useful, if it related to programs and services, or how a province's health and education systems worked. Others suggested the package contain specific information on local schools and primary care physicians and pediatricians specializing in ASD so families could be placed on the correct wait-list immediately. One parent explained this would avoid "... hopping around all over the place, and you know, not finding out about certain programs until, you know, weeks and months later." Other common recommendations were for the provision of a list of current service providers, community groups, other families who have children with ASD, funding opportunities, local programs and websites.

\section{Strategies to promote continuity and coordination of services}

Most parents clearly expressed the need to have specific information targeted to families who have a child on the autism spectrum when facing mandatory relocation, especially for those early in the diagnosis phase, who have no previous experience navigating the health and education systems. Recommendations clustered around facilitating a smooth transition to reduce the amount of time spent waiting for services and supports at a new location, rather than "blindly navigating."

Reduce posting frequency. All participants lamented the impact of relocation on their child's ability to access or continue with required services, with two asserting that staying in one location as long as possible was a desired goal. One parent recapped:

[The military] send[s] you to a new location, then you wait 2 or 3 years to get on this wait-list, and then they boot you after you're there for 4 years, or 5 years, well, you know now, now she's only getting 1 or 2 years of support.

Medical record transfer. Parents strongly endorsed this area as a priority for improvement. Recommendations made by parents about the transfer of medical and educational records underscored a need to expedite the process for families through supports and/or through mechanisms for them to own the process entirely or share responsibility. Nearly half of parents specifically indicated they would like help with records transfer, while others expressed a lack of trust in leaving such an important component of their transition in the hands of another person. The potential for an electronic file transfer that the military would manage was recognized by participants, and one commented: "if they're going to have that file-share system, then it should be Canada-wide, so that if we get posted ... I don't have to lug two totes around with me when I'm going to see people."

Some participants spoke to the value of maintaining their own set of complete records for health and educational purposes. One participant reflected:

The biggest help that I've ever had is the fact that I've kept all my paperwork. Like, it's saved me so much headache ... I don't let the movers pack it. I take it with me when we move, like, in the car ... if I show up at a doctor's office, or I show up at the school, or if I move 10 times from now, I'll be able to just, kind of, show people.

Advocacy. All parents recommended taking the initiative to advocate for their child with ASD to optimize continuity and coordination of services at the time of posting. This included being proactive in finding information from multiple sources, being proactive in the search for educational supports early in the posting process, being put on wait-lists for services, personal record keeping/transfer, and fundraising for service provision.

One parent explained that "years" are saved by “just knowing what's really out there, versus just waiting for it to show it[self]." Beginning the search as soon as a posting was announced, or even rumoured, was a common suggestion in order to "get the ball rolling" as early as possible. For example, a parent advised that "as soon as you physically can, you're contacting the [school] people 
and giving them the heads up." Other parents stated they would "at least be following up on referrals on a weekly basis to make sure we've got something set up when we walk in the door." Parents emphatically advised, "you are your own best advocate. Push hard and don't give up."

For some parents, the need for advocacy was sufficiently strong as to be expressed in terms of a battle that must be fought, advising that parents must "fight for their kid." One parent spoke to this: "... you need to fight for what you need. At the end of the day, we're the ones that have to stick up for our kids." While this was a common suggestion, one participant admitted this process of relentless advocacy was "beyond exhausting." However, these strongly held views on self-advocacy did not preclude a concomitant recommendation for the enlistment of others to advocate on behalf of a child. As mentioned, the mobilization of advocacy efforts by previous health care providers was also encouraged. Having a MFRC staff member to assist with transition also was seen as a valuable asset with regard to advocacy: "so that when we arrived, this person is here to act as an advocate on our behalf, who knows the in's and out's of the education system and the health system." These recommendations were also seen as provisions to assist families in advocating for themselves as one participant indicated:

If you're going to trust someone else to do it for you, stay on top of the situation, always calling, always following up. ... You can say, 'Okay, can you send this referral for me?' But you need to be on it. You need to be the one knowing what's going on, when, where, why.

\section{DISCUSSION}

While literature focusing on the effect of military-related relocation is scarce, what has been developed focuses on the American context and indicates that frequent relocation can be problematic. ${ }^{1}$ This is especially true for children with ASD. ${ }^{16,17}$ This study is among the first to describe the recommendations of military families of children with ASD arising from their experiences with health and education system access during mandatory relocation. As such, this study addresses a gap in knowledge about how to facilitate navigation through the Canadian health care system for this population of military families. The results of this study are supported by other recent findings, as well as initiatives within the CAF and Canadian health provider organizations. They also have implications for additional research, policy, and programming for Canadian military families of children with ASD.

The recommendations made by participants in this study included communication strategies, such as mentoring programs, as well as strategies related to promoting continuity and coordination of health care services, such as assistance with transferring health services from one region or province to another. These recommendations are supported by earlier reports from the Canadian Pediatric Society, ${ }^{31}$ the College of Family Physicians of Canada, ${ }^{32}$ the Department of National Defence and Canadian Forces Ombudsman ${ }^{4}$ and Canada's Defence Policy, Strong, Secure, Engaged. ${ }^{33}$ Furthermore, a recent Canadian study undertaken to document military family delays in accessing primary and specialist care after relocation echoes these recommendations. ${ }^{34}$ Other recent Canadian research on military-connected children's access to special education ${ }^{35}$ makes noticeably similar recommendations for support: the need for strong selfand assisted-advocacy; the need for better information on relocation; the desire for a support group; and outreach for families living off base. Evidently, military families with special education needs are facing parallel challenges to those navigating health care systems in Canada.

Recent developments on the international and national stage have signalled military institutions' recognition of the unique challenges faced by military families who have a child with special needs. A notable example in the United States is the passing of legislation known as The Interstate Compact on Education and Opportunities for Military Children, ${ }^{24}$ which addresses education transition issues by establishing a consistent policy across jurisdictions, by providing military-related awareness training for educators and by instituting provisions for efficient transfer of documents and supports - all of which could serve as a model for Canada. ${ }^{36}$ On a much smaller scale, the CAF has piloted programs, based on similar strategies in the United Kingdom ${ }^{37}$ and United States, ${ }^{38}$ at several Canadian bases to facilitate transitions for children with special needs through the engagement of a special needs coordinator. ${ }^{38}$ Other programs, such as the Canadian military family outreach Family Information Line, ${ }^{39}$ which provides information and support to families who live off base, aim to address communication deficits in ways reflected by the participants in this study. The 30-day wait to access to health care in a new province has been waived for Canadian military families; the Minister of 
Defence has also begun discussions with the provinces for Seamless Canada, ${ }^{40}$ an initiative to improve education and health service coordination between provinces and territories for military families.

Despite these efforts, frequent relocation still presents significant challenges for families with special needs. Implementing a number of the ideas expressed by the participants in this research would reflect a classic bottom-up approach to tackling the relentless problem of repeatedly "starting from scratch" with each relocation and make further gains toward supporting these families.

Participants strongly endorsed the creation of a "network of shepherds" who could provide both formal and informal support and knowledge. A mentoring program that aligns with this description was created and implemented at five Wings and Squadrons by the Royal Canadian Air Force (RCAF) in 2014. ${ }^{41}$ Within this program, the military unit and the local MFRCs engaged a team of local volunteers (adult family members of serving personnel) to act as sponsors to incoming families or families affected by duty-related separations. The sponsors introduced families to the unit, facilitatede access to local supports and services, and helped families settle into the new area. This program included many of the structural components participants in this study desired. It had the goal of facilitating transition; there was a significant role for the MFRCs as a source of centralized information and was the location of a "point person" to provide assistance, volunteer sponsors were military members, or family of military members, who provided support and information informally; and the communication between sponsors/mentors and the incoming families preceded their arrival. If it existed outside the chain of command, it might have been in a better position to ensure members' careers not be impacted through the disclosure of personal health information. The results of this study could provide an evidence-based rationale for the expansion and adaptation of this program for families who have children with ASD or other special needs, as well as additional research to develop and evaluate such a program to ensure its effectiveness.

Other recommendations resulting from this study have not, to the authors' knowledge, been implemented, but have the potential to address the challenges of health and education system access during relocation. Participants repeatedly described difficulty transferring services and health records. There were a number of recommendations made that could be explored further to assist with this problem. For example, a child's pediatrician/medical facility in the current province could refer to a pediatrician in the new province, outlining a summary of the child's current skills and treatment needs. Alternately, the new province's providers could proactively request the patient's records or verbal "handover" from the previous province's providers, preventing delays through repeated assessments prior to starting treatments. Medical passports could enable patients/caregivers to share medical/health files online. Further options include the identification of a primary care doctor in the new location prior to relocation and communication between caregivers (doctors, therapists) via phone or videoconferencing when needed.

Discontinuities in care created by repeatedly starting at the bottom of service wait-lists after each move might be managed through alignment of wait-lists across locations that honour wait-list positions from previous postings where possible; a strategy similar to the model employed for the US organ transplant waitlist. ${ }^{42}$ Pediatricians and other services that commonly have wait-lists could also simply save spots on the list for children from military-connected families who are newly posted.

\section{Limitations}

There are limits around the generalizability of qualitative research. The study sample consists of diversity across ranks, which helps ensure shared essential experiences have been captured. However, information about children's comorbidities, parents' ages or civilian parent's employment status - factors which may have bearing on their experiences - were not obtained. Those who elect to participate in research may have strong perspectives on the issues, so neutral framing was used to elicit perspectives on their experiences, rather than to presume there were challenges.

\section{Conclusion}

This study explored opportunities to support military families navigating service systems for children with ASD from the perspective of those families. Improved support and communication and strategies for improving continuity and coordination of service would help support Canadian military families with children who have special needs. These assertions are supported by research and policy initiatives both nationally and internationally, however, more research is required to understand the nature of the issues experienced by Canadian families, to create support effective evidence-informed systems. 


\section{REFERENCES}

1. Cramm H, McColl MA, Aiken AB, et al. The mental health of military-connected children: a scoping review. J Child Fam Stud. 2019;28(7):1725-35. https://doi. org/10.1007/s10826-019-01402-y.

2. Aronson KR, Perkins DF. Challenges faced by military families: perceptions of United States Marine Corps school liaisons. J Child Fam Stud. 2013;22(4):516-25. https://doi.org/10.1007/s10826-012-9605-1.

3. Mmari KN, Bradshaw CP, Sudhinaraset M, et al. Exploring the role of social connectedness among military youth: perceptions from youth, parents, and school personnel. Child Youth Care Forum. 2009;39(5):351-66. https://doi.org/10.1007/s10566-010-9109-3.

4. National Defence and Canadian Forces Ombudsman. On the homefront: assessing the well-being of Canada's military families in the new millennium. Ottawa, ON: Office of the Ombudsman; 2013.

5. Jagger JC, Lederer S. Impact of geographic mobility on military children's access to special education services. Child Sch. 2014;36(1):15-22. https://doi. org/10.1093/cs/cdt046.

6. Aronson KR, Kyler SJ, Moeller JD, et al. Understanding military families who have dependents with special health care and/or educational needs. Disabil Health J. 2016;9(3):423-30. https://doi.org/10.1016/j. dhjo.2016.03.002. Medline:27157311

7. National Council on Disability. United States Marine Corps exceptional family members: how to improve access to healthcare, special education, and long-term supports and services for family members with disabilities. Washington, DC: National Council on Disability; 2011.

8. Classen AI. Needs of military families: family and educator perspectives [dissertation]. Lawrence, KS: University of Kansas; 2014.

9. Military Family Services. Inclusion policy for individuals with special needs [report on the Internet]. Ottawa, ON: Canadian Forces Morale and Welfare Services; 2015. Available from: https://www.cafconnection.ca/ getmedia/144a919b-00e6-4752-bb6a-578d4b85dcb5/ Inclusion-Policy-31-December-2015.aspx.

10. Government of Canada. Austism spectrum disorder among children and youth in Canada 2018 [report on the Internet]. Ottawa, ON: Government of Canada; 2018 [updated 2018 Apr 9; cited 2018 Jul 9]. Available from: https://www.canada.ca/en/publichealth/services/publications/diseases-conditions/ autism-spectrum-disorder-children-youth-canada2018.html.

11. Williams TV, Schone EM, Archibald ND, et al. A national assessment of children with special health care needs: prevalence of special needs and use of health care services among children in the military health system. Pediatrics. 2004;114(2):384-93. https://doi. org/10.1542/peds.114.2.384. Medline: 15286221

12. Diallo FB, Fombonne É, Kisely S, et al. Prevalence and correlates of autism spectrum disorders in Québec [Prévalence et corrélats des troubles du spectre de l'autisme au Québec]. Can J Psychiatry. 2018;63(4):231-9. https://doi.org/10.1177/0706743717737031. Medline:29056086

13. American Psychiatric Association. Diagnostic and statistical manual of mental disorders (DSM-5). 5 th ed. Washington, DC: American Psychiatric Association; 2013.

14. Dawson G. Early behavioral intervention, brain plasticity, and the prevention of autism spectrum disorder. Dev Psychopathol. 2008;20(3):775-803. https://doi.org/10.1017/s0954579408000370. Medline: 18606031

15. Penner M, King GA, Hartman L, et al. Community general pediatricians' perspectives on providing autism diagnoses in Ontario, Canada: a qualitative study. J Dev Behav Pediatr. 2017;38(8):593-602. https:// doi.org/10.1097/dbp.0000000000000483. Medline:28937447

16. Davis JM, Finke EH. The experience of military families with children with autism spectrum disorders during relocation and separation. J Autism Dev Disord. 2015;45(7):2019-34. https://doi.org/10.1007/ s10803-015-2364-2. Medline:25604584

17. Davis J, Finke E, Hickerson B. Service delivery experiences and intervention needs of military families with children with ASD. J Autism Dev Disord. 2016;46(5):1748-61. https://doi.org/10.1007/ s10803-016-2706-8. Medline:26780908

18. Cramm H, Norris D, Tam-Seto L, et al. The current state of military family research. J Mil Veteran Fam Health. 2015;1(2):8-12. https://doi.org/10.3138/ jmvfh.3287.

19. Wang Z, Aitken N. Impacts of military lifestyle on military families: results from the quality of life survey of Canadian Armed Forces Spouses. DRDC-RDDC2016-R012. Ottawa, ON: Defence Research and Development Canada; 2016.

20. Manser L. State of military families in Canada: issues facing regular force members and their families. Ottawa, ON: Canadian Forces Morale and Welfare Services; 2018 [cited 2020 Mar 4].

21. Manser L. Relocation experiences: the experiences of military families with relocations due to postingssurvey results. Ottawa, ON: Military Family Services, Canadian Forces Morale and Welfare Services; 2018.

22. Skomorovsky A, Wang Z, Wolejszo S. The impact of relocations on military families. DRDC-RDDC2016-L300. Ottawa, ON: Defence Research and Development Canada; 2016. 
23. Bullock A, Skomorovksy A. Children's positive experiences growing up in Canadian military households. J Mil Vet Fam Health. 2016;2(2):21-8. https://doi. org/10.3138/jmvfh.3837.

24. Federal Register. Interstate compact on educational opportunity for military children. Document number 2016-30110. Washington, DC: Department of Defense; 2016 Dec 20 [cited 2020 Mar 4]. Available from: https://www.federalregister.gov/documents/ 2016/12/20/2016-30110/interstate-compact-oneducational-opportunity-for-military-children.

25. Canadian Forces Morale \& Wellness Services (CFMWS). Military family resource centres - backgrounder [homepage on the Internet]. Ottawa, ON: CFMWS; 2018. Available from: https://www.cfmws.com/en/ AboutUs/Library/MediaCentre/Archive/Pages/ MilitaryFamilyServicesBackgrounder.aspx.

26. Cramm H, Smith G, Samdup D, et al. Navigating health care systems for military-connected children with autism spectrum disorder: a qualitative study of military families experiencing mandatory relocation. Paediatr Child Health. 2019;24(7):478-84. https:// doi.org/10.1093/pch/pxy179. Medline:31660044

27. Creswell JW. Qualitative inquiry and research design: choosing among five approaches. $3 \mathrm{rd}$ ed. Thousand Oaks, CA: SAGE Publications; 2012.

28. Lester $S$. An introduction to phenomenological research [Internet]. Somerset, UK: Stan Lester Developments; 1999 [cited 2018 Feb 8]. Available from: https://www.semanticscholar.org/paper/Anintroduction-to-phenomenological-research-Lester/ 02b321149f8a77ce112a0664e40cc7780190f0c4.

29. Strauss A, Corbin J. Basics of qualitative research: techniques and procedures for developing grounded theory. 2nd ed. Thousand Oaks, CA: SAGE Publications; 1998.

30. Tong A, Sainsbury P, Craig JW. Consolidated criteria for reporting qualitative research (COREQ): a 32item checklist for interviews and focus groups. Int J Qual Health Care. 2007;19(6):349-57. https://doi. org/10.1093/intqhe/mzm042. Medline: 17872937

31. Rowan-Legg A. Caring for children and youth from Canadian military families: special considerations. Ottawa, ON: Canadian Paediatric Society; 2016.

32. College of Family Physicians of Canada (CFPC). Family physicians working with military families [Internet]. Mississauga, ON: CFPC; 2017 [cited 2020 Mar 4]. Available from: https://portal.cfpc.ca/resourcesdocs/ uploadedFiles/Military\%20Family\%20Physician\%20 Guide_E.pdf.

33. Government of Canada National Defence and Canadian Armed Forces. Strong, secure, engaged: Canada's defence policy [Internet]. (Government of Canada Publications, no. D2-386/2017E-PDF). Ottawa, ON: Department of National Defence; 2017 [cited 2020
Mar 4]. 113 p. Available from: http://publications. gc.ca/site/eng/9.835971/publication.html.

34. Mahar A, Aiken, A, Cramm, H, et al. Access to healthcare and medical health services use for Canadian military families posted to Ontario: a retrospective cohort study. J Mil Vet Fam Health. 2018;4(2):61-70. https:// doi.org/10.3138/jmvfh.2018-0014.

35. Ostler K, Norris D, Cramm H. Geographic mobility and special education services: understanding the experiences of Canadian military families. J Mil Vet Fam Health. 2018;4(2):71-80. https://doi.org/10.3138/ jmvfh.2017-0010.

36. Children's Education Advisory Service (CEAS). A guide for service families: UK education systems [Internet]. Wiltshire, UK: Ministry of Defence; 2013 [cited 2020 Mar 4]. 9 p. Available from: https://assets. publishing.service.gov.uk/government/uploads/system/ uploads/attachment_data/file/172954/ceas_brochure_ lores_spreads.pdf.

37. Army Families Federation. Special educationsl needs [homepage on the Internet]. Andover, UK: Army Families Federation; c2019 [cited 2020 Mar 4]. Available from: https://aff.org.uk/advice/education-childcare/ special-educational-needs/.

38. Aronson KR, Caldwell LL, Perkins DF, et al. Assisting children and families with military-related disruptions: the United States Marine Corps School liaison program. Psychol Sch. 2011;48(10):998-1015. https:// doi.org/10.1002/pits.20608.

39. Canadian Forces Morale \& Welfare Services. Family information line: military family services [homepage on the Internet]. Ottawa, ON: Canadian Forces Morale and Welfare Services; 2016 [cited 2020 Mar 4]. Available from: https://www.cafconnection.ca/National/ Stay-Connected/Family-Information-Line.aspx.

40. Galloway G. Ottawa asks provinces, territories to make life easier for military families reassigned to new locations. The Globe and Mail; 2018 Jun 27.

41. Royal Canadian Air Force. The RCAF family sponsor program [homepage on the Internet]. Ottawa, ON: Government of Canada; 2017 [updated 2019 Dec 19; cited 2020 Mar 4]. Available from: http://www.rcaf-arc. forces.gc.ca/en/family-support-team/family-sponsorprogram.page.

42. US Department of Health and Human Services. Organ procurement and transplantation network [homepage on the Internet]. Richmond, VA: US Department of Health \& Human Services; c2019 [cited 2020 Mar 4]. Available from: https://optn.transplant.hrsa.gov/.

\section{AUTHOR INFORMATION}

Heidi Cramm, PhD, OT Reg. (Ont.), is Associate Professor, School of Rehabilitation Therapy, Queen's University. Dr. 
Cramm is a military and Veteran family health researcher, with a focus on mental health within family systems. http:// orcid.org/0000-0002-8805-063X

Ashley Williams, MScOT, $\mathrm{PhD}(\mathrm{c})$, OT Reg. (Ont.), is a doctoral candidate in the School of Rehabilitation Therapy at Queen's University. Ms. Williams is a military, Veteran, and family researcher in training focusing on military-tocivilian transition and health service access. https://orcid. org/0000-0002-0384-8280

Dawa Samdup, MBBS, FRCP (C), is Associate Professor, Department of Pediatrics, Developmental Pediatrician, KidsInclusive Centre for Child \& Youth Development. She is an active clinician and researcher involved in the care of children and youth with neurodevelopmental disorders. She is also involved in multi-centre research on FASD, cerebral palsy, Autism Spectrum Disorder, and patient-oriented and health care service access research.

Lucia Rühland, MSc, is a Research Project Manager at the School of Rehabilitation Therapy at Queen's University. Ms. Rühland has an interest in research methods.

Ronald Garth Smith, MBBS, FRCP(C), is Associate Professor, Department of Pediatrics, Developmental Pediatrician, Medical Director, KidsInclusive Centre for
Child \& Youth Development. He is an active clinician and researcher involved in the care of children and youth with a range of developmental disabilities.

\section{COMPETING INTERESTS}

None declared.

This article has been peer reviewed.

\section{CONTRIBUTORS}

All authors conceived, designed, researched, and drafted the manuscript and approved the final version submitted for publication.

\section{FUNDING}

None declared.

\section{ACKNOWLEDGEMENTS}

We would like to thank the military families who shared their experiences with the research team, and the Queen's University Senate Advisory Research Committee Principal's Development Fund, which funded this study. 